\title{
Características agronômicas de seis cultivares de amendoim cultivadas em sistema convencional e de semeadura direta
}

\author{
Gabriel M. Fachin ${ }^{1}$, José B. Duarte Júnior², Cláudio A. da S. Glier³, \\ Chrismam R. Mrozinski ${ }^{4}$, Antonio C. T. da $\operatorname{Costa}^{5}$ \& Vandeir F. Guimarães ${ }^{6}$
}

${ }^{1}$ UNISEP. Dois Vizinhos, PR. E-mail: gabrielm_fachin@hotmail.com (Autor correspondente)

${ }^{2}$ CCA/UNIOESTE. Marechal Cândido Rondon, PR. E-mail: jose.junior6@unioeste.br

${ }^{3}$ Syngenta Seeds - Marketing e Vendas. Campos de Júlio, MT. E-mail: chrisrovani@hotmail.com

${ }^{4}$ COAMO Agroindustrial Cooperativa. Nova Santa Rosa, PR. E-mail: claudiogli@yahoo.com.br

${ }^{5}$ CCA/UNIOESTE. Marechal Cândido Rondon, PR. E-mail: antonio.costa2@unioeste.br

${ }^{6}$ CCA/UNIOESTE. Marechal Cândido Rondon, PR. E-mail: vandeirfg@yahoo.com.br

\section{Palavras-chave:}

Arachis hypogaea L.

manejo conservacionista de solo

componentes de rendimento

\begin{abstract}
R E S U M O
Objetivou-se no presente trabalho avaliar o desempenho agronômico de seis cultivares de amendoim em sistema convencional e de semeadura direta nos municípios de Marechal Cândido Rondon e Tupãssi, PR, na safra 2011/2012. O delineamento experimental adotado foi de blocos ao acaso com quatro repetições num esquema de parcelas subdivididas. Foram utilizados, nas parcelas, dois sistemas de manejo de solo, o sistema convencional e sistema de semeadura direta e seis cultivares de amendoim de hábito de crescimento contrastante, um de porte ereto e cinco de porte rasteiro, nas subparcelas. Não houve diferença entre os sistemas de manejo conservacionista e convencional no rendimento de vagens e grãos, no número de estruturas reprodutivas nem no índice de rendimento de grãos do amendoim, nos dois locais avaliados. No município de Marechal Cândido Rondon as maiores produtividades foram obtidas pelos cultivares IAC 503, IAC Caiapó, IAC 213, Runner IAC 886 e Cavalo, respectivamente, independentemente do sistema de manejo de solo. Em Tupãssi a produtividade de grãos variou apenas entre os tipos de ramificação dos materiais cujos maiores valores foram observados para cultivares de ramificação alternada (Virgínia).
\end{abstract}

Key words:

Arachis hypogaea $\mathrm{L}$.

soil conservation practice

yield components

\section{Agronomic characteristics of six peanut cultivars grown in conventional and no-tillage system}

\begin{abstract}
A B S T R A C T
This study aimed to evaluate the agronomic performance of six peanut cultivars in conventional and no-tillage systems in the municipality of Marechal Cândido Rondon and Tupãssi, PR, in the 2011/2012 harvest. The experimental design was in randomized block with four replications in a split plot. Plots were used in two systems of soil management, the conventional and no-tillage system and six peanut cultivars of contrasting growth habit, one of erect and five prostrate, in the subplots. There was no difference between the systems of conservation and conventional tillage on the yield of beans and grains, the number of reproductive structures and in the index grain yield in two evaluated locations. The highest yields were obtained for the Virginia type cultivars independently of the system of soil management, being IAC 503, IAC Caiapó, IAC 213, Runner IAC 886 and Cavalo respectively in Marechal Cândido Rondon. In the municipality of Tupãssi, grain yield varied only between types of materials branch, and the highest values observed for alternating branching cultivars (Virginia).
\end{abstract}

\section{INTRODUÇÃo}

O amendoim (Arachis hypogaea L.) ocupou papel de destaque entre as culturas mais produzidas no Brasil, até início da década de 70; entretanto, algumas questões políticas, tecnológicas e mercadológicas, acarretaram drástica redução na área cultivada no país. O Paraná, um dos maiores estados produtores, diminuiu muito a produção desta oleaginosa correspondendo, atualmente, por apenas 6,4 mil toneladas de grãos $(3,5 \%)$, a qual se concentra no estado de São Paulo, responsável por 78\% da produção nacional (CONAB, 2012).
O mercado consumidor de amendoim no Brasil é dividido em dois segmentos: na confeitaria e no consumo in natura. Em decorrência de que os cultivares de amendoim apresentam características diferenciadas para cada segmento de mercado. Desta forma, o consumo in natura é mais favorecido pelas cultivares do tipo agronômico Valência ou Spanish, por apresentarem grãos médios de coloração vermelha. Por outro lado, o mercado de confeitaria tem preferência pelos grãos grandes e de coloração bege, representados pelos cultivares rasteiros do tipo Virgínia (Santos, 2000). 
No Paraná, tal como na maior parte do Brasil, os cultivares de amendoim são produzidos em sistema convencional de manejo de solo (Godoy et al., 2005) porém com o tempo o solo cultivado com preparo mecânico tende a ter sua estrutura alterada pelo fracionamento dos agregados com redução do volume de macroporos e promoção do aumento da densidade do solo (Panachuki et al., 2006).

O sistema de semeadura direta contribui, por ser um sistema conservacionista de manejo do solo, significativamente para a diminuição da erosão em relação aos preparos convencionais (Bertol et al., 2007; Prando et al., 2010), uma vez que o revolvimento ocorre apenas na linha de semeadura mantendo os restos da cultura anterior na superfície, protegendo o solo contra os efeitos nocivos dos impactos das gotas da chuva (Cassol et al., 2007), permitindo maior infiltração de água no perfil (Llanillo et al., 2006; Prando et al., 2010), apresentando, assim, vantagens econômicas e ambientais para várias culturas de interesse econômico no Brasil.

Com a evolução da colheita mecanizada e o crescente melhoramento de cultivares mais produtivos e com ciclo reduzido tem-se aumentado as áreas cultivadas; desta forma, os produtores de amendoim buscam cada vez mais a inserção de tecnologias que reduzam o tempo e a mão-de-obra na produção.

Desde o final da década de 70 foram constatadas, em pesquisas em condições norte-americanas, perdas entre 19 e $62 \%$ na produção de vagens e grãos de amendoim nos sistemas conservacionistas de manejo do solo (Grichar \& Boswell, 1987; Wright \& Porter, 1991). Essas reduções de produção foram atribuídas aos problemas de compactação do solo (Colvin et al., 1988) e à maior incidência de doenças nas vagens (Jordan et al., 2001). Por outro lado, relatos sobre resultados favoráveis aos sistemas conservacionistas já foram obtidos indicando, assim, a possibilidade de obtenção de aumentos na produção de até $10 \%$ em relação aos sistemas convencionais de manejo de solo (Hartzog \& Adams, 1989; Wright, 1991).

Além dos aumentos em produção em sistemas conservacionistas de manejo de solo Porter \& Wright (1991) encontraram diminuição da incidência de Cercospora arachidicola e redução de danos ocasionados por ataque do tripes e pela incidência de virose TSWV, além da manutenção da umidade do solo e redução do custo de produção.

Em condições brasileiras estudos já têm sinalizado sucesso na adoção de sistemas conservacionistas de solo para a cultura do amendoim. Bolonhezi et al. (2007) não observaram diferença entre os sistemas de manejo conservacionistas e convencional na produção de vagens e grãos nem no número de estruturas reprodutivas de amendoim; entretanto; resultados para condições semelhantes mencionam aumentos significativos na produção de vagens quando se adotam sistemas conservacionistas (Tasso Júnior, 2003).

Assim, tornam-se necessárias pesquisas nas condições de solo da região Oeste do Paraná para que se possa qualificar e quantificar as limitações e as características do sistema de semeadura direta em relação ao sistema convencional para esta oleaginosa. Diante do exposto o objetivo neste trabalho foi avaliar o desempenho agronômico de seis cultivares de amendoim em sistema convencional e de semeadura direta.

\section{MATerial e Métodos}

Este trabalho constou de experimentação conduzida a campo em dois municípios da região Oeste do Paraná, na safra 2011/2012. Em Marechal Cândido Rondon, situado na latitude $24^{\circ} 33^{\prime} 22^{\prime \prime} \mathrm{S}$ e longitude $54^{\circ} 03^{\prime} 24^{\prime \prime} \mathrm{W}$, com altitude aproximada de $400 \mathrm{~m}$ acima do nível do mar e no município de Tupãssi, na latitude $24^{\circ} 15^{\prime} 16^{\prime \prime}$ S e longitude $53^{\circ} 30^{\prime} 42^{\prime \prime} \mathrm{W}$, com altitude aproximada de $540 \mathrm{~m}$. Em ambos os locais o solo foi classificado como Latossolo Vermelho eutroférrico de textura muito argilosa (EMBRAPA, 2006), os quais eram manejados em sistema de semeadura direta por seis anos consecutivos. Os dados meteorológicos foram coletados nos dois locais e estão apresentados na Figura 1.

Prévio à implantação do experimento foram coletadas amostras para determinação das características químicas nas profundidades de $0-10$ e $10-20 \mathrm{~cm}$ e se determinaram as propriedades físicas densidade, macroporosidade e microporosidade em seis profundidades, assim como a composição granulométrica (Tabela 1).

O delineamento experimental adotado foi em blocos ao acaso (DBC), com quatro repetições em um esquema de parcelas subdivididas. Dois sistemas de manejo de solo, o sistema convencional (SC) e o sistema de semeadura direta (SSD) foram dispostos nas parcelas, e seis cultivares de amendoim de hábito de crescimento contrastante, sendo Cavalo, Runner IAC 886, IAC 213, IAC 503 e IAC Caiapó de porte rasteiro (Virgína) e IAPAR 25 Tição de porte ereto (Valência ou Spanish), dispostos nas subparcelas. O SSD se constituiu da semeadura sob palhada remanescente de aveia branca (Avena sativa L.) cultivar IAPAR 126, a qual produziu 3.447 e $2.975 \mathrm{~kg} \mathrm{ha}^{-1}$ de matéria seca na ocasião da semeadura, em Marechal Cândido Rondon e Tupãssi, respectivamente; já o SC foi efetuado através de uma subsolagem a $35 \mathrm{~cm}$ de profundidade seguida de duas gradagens niveladoras, visando à incorporação e destruição dos restos culturais da espécie de planta de cobertura.

As parcelas apresentavam $5 \mathrm{~m}$ de largura por $25,2 \mathrm{~m}$ de comprimento e eram compostas de seis subparcelas ou unidades experimentais com seis linhas de $5 \mathrm{~m}$ de comprimento espaçadas a $0,7 \mathrm{~m}$, totalizando $21 \mathrm{~m}^{2}$. A área útil foi composta de 2 linhas centrais de $3 \mathrm{~m}$ de comprimento espaçadas a $0,7 \mathrm{~m}$ totalizando $4,2 \mathrm{~m}^{2}$.

A recomendação da calagem foi feita pelo método da saturação por bases, elevando-a para $70 \%$ em que, assim como a adubação, foi baseada na análise do solo da área experimental e na expectativa de produtividade de grãos de $4.000 \mathrm{~kg} \mathrm{ha}^{-1}$. A calagem foi realizada a lanço, trinta dias antes da implantação do experimento, na dose de $1,5 \mathrm{t} \mathrm{ha}^{-1}$ de calcário calcítico e a adubação foi feita na linha de semeadura pela adição de $480 \mathrm{~kg}$ ha $^{-1}$ do formulado 0-20-15. O número de plantas por metro foi calculado com base na porcentagem de germinação específica de 
A.

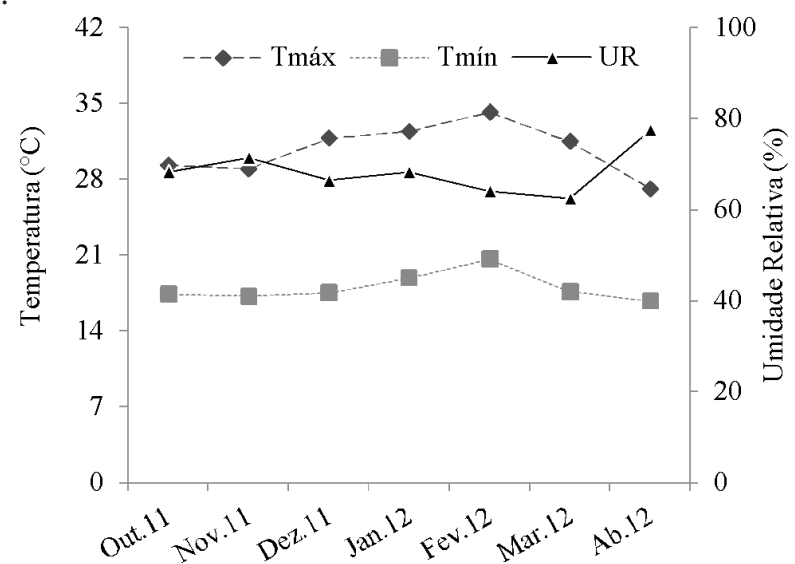

C.

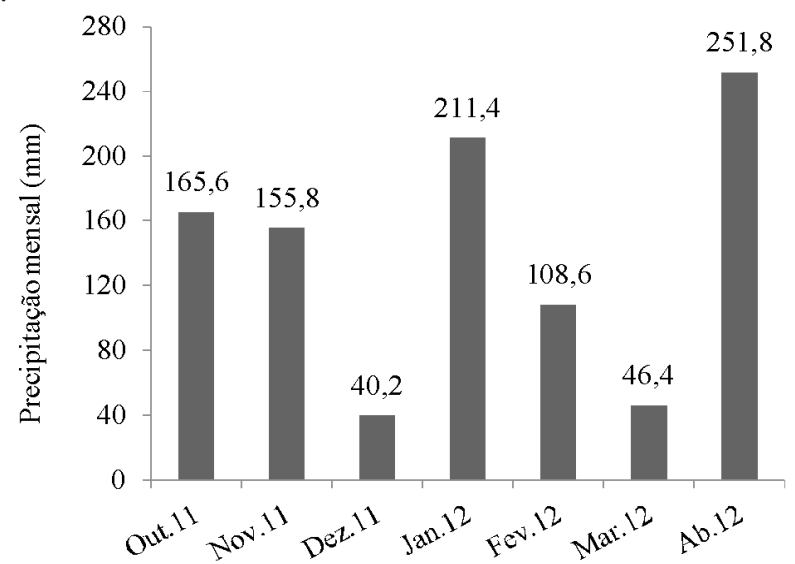

B.

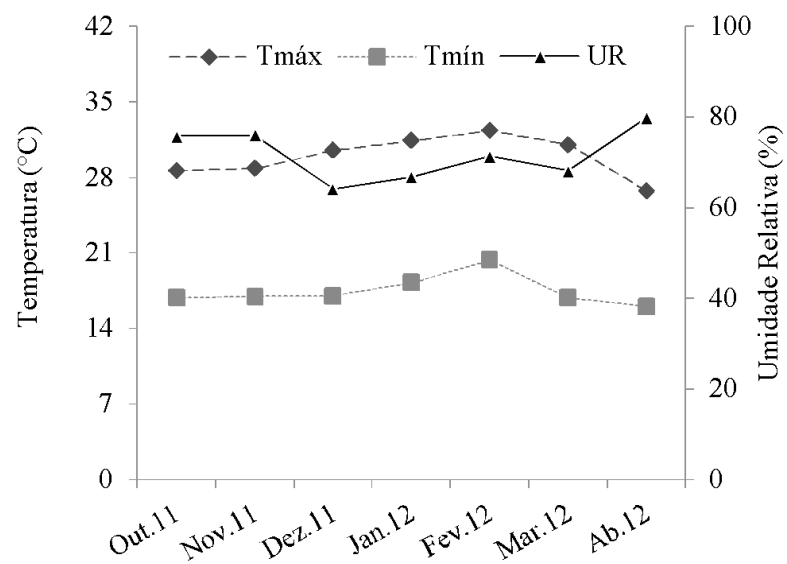

D.

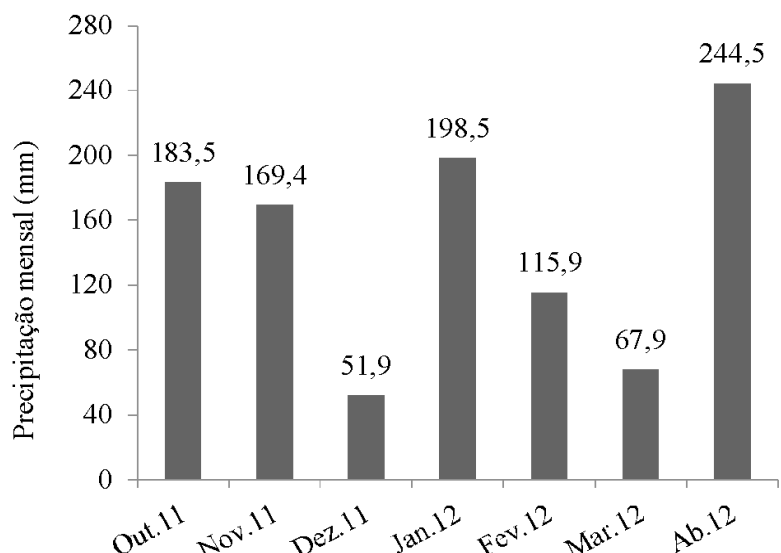

Figura 1. Dados climáticos durante o período de outubro de 2011 a abril de 2012. A e B. Temperatura máxima (Tmáx), Temperatura mínima (Tmín) e Umidade relativa do ar (UR); C e D. Precipitação total (Ppt) em Marechal Cândido Rondon e Tupãssi, PR, respectivamente

Tabela 1. Propriedades físicas densidade (DE), macroporosidade (MA), microporosidade (MI), composição granulométrica e características químicas dos solos utilizados para a pesquisa nos municípios de Marechal Cândido Rondon e Tupãssi, PR

\begin{tabular}{|c|c|c|c|c|c|c|}
\hline \multirow{3}{*}{$\begin{array}{c}\text { Análise física/ } \\
\text { Profundidade (cm) }\end{array}$} & \multicolumn{3}{|c|}{$\begin{array}{l}\text { Marechal Cândido } \\
\text { Rondon }\end{array}$} & \multicolumn{3}{|c|}{ Tupãssi } \\
\hline & \multirow{2}{*}{$\begin{array}{c}\mathrm{DE} \\
\left(\mathrm{t} \mathrm{m}^{-3}\right)\end{array}$} & MA & MI & \multirow{2}{*}{$\begin{array}{c}\mathrm{DE} \\
\left(\mathrm{t} \mathrm{m}^{-3}\right)\end{array}$} & MA & MI \\
\hline & & \multicolumn{2}{|c|}{$(\%)$} & & \multicolumn{2}{|c|}{$(\%)$} \\
\hline $0-10$ & 1,73 & 9,48 & 58,65 & 1,65 & 10,57 & 62,24 \\
\hline $10-20$ & 1,77 & 9,33 & 55,87 & 1,71 & 8,25 & 58,22 \\
\hline $20-30$ & 1,71 & 12,66 & 56,74 & 1,62 & 5,71 & 61,33 \\
\hline $30-40$ & 1,80 & 10,37 & 58,96 & 1,59 & 5,73 & 61,46 \\
\hline $40-50$ & 1,78 & 7,72 & 59,43 & 1,52 & 8,05 & 61,51 \\
\hline $50-60$ & 1,72 & 10,85 & 58,99 & 1,51 & 8,28 & 61,06 \\
\hline Argila $\left(\mathrm{g} \mathrm{kg}^{-1}\right)$ & \multicolumn{3}{|c|}{670} & \multicolumn{3}{|c|}{640} \\
\hline Silte $\left(\mathrm{g} \mathrm{kg}^{-1}\right)$ & \multicolumn{3}{|c|}{180} & \multicolumn{3}{|c|}{160} \\
\hline Areia $\left(\mathrm{g} \mathrm{kg}^{-1}\right)$ & \multicolumn{3}{|c|}{150} & \multicolumn{3}{|c|}{200} \\
\hline \multirow{2}{*}{ Análise química } & \multicolumn{6}{|c|}{ Profundidade (cm) } \\
\hline & $0-10$ & & $10-20$ & $0-10$ & & $10-20$ \\
\hline $\mathrm{pH} \mathrm{CaCl}{ }_{2}$ & 4,8 & & 5,0 & 4,60 & & 4,90 \\
\hline $\mathrm{C}\left(\mathrm{g} \mathrm{dm}^{-3}\right)$ & 15,1 & & 13,0 & 14,80 & & 12,79 \\
\hline$P\left(\mathrm{mg} \mathrm{dm}^{-3}\right)$ & 13,4 & & 8,6 & 4,21 & & 3,60 \\
\hline $\mathrm{H}+\mathrm{Al}$ & 3,4 & & 3,6 & 8,73 & & 5,60 \\
\hline $\mathrm{Ca}^{2+}\left(\mathrm{cmol}_{\mathrm{c}} \mathrm{dm}^{-3}\right)$ & 4,6 & & 4,3 & 4,22 & & 3,60 \\
\hline $\mathrm{Mg}^{2+}\left(\mathrm{cmol}_{\mathrm{c}} \mathrm{dm}^{-3}\right)$ & 1,7 & & 1,1 & 0,86 & & 0,31 \\
\hline $\mathrm{K}^{+}\left(\mathrm{cmol}_{\mathrm{c}} \mathrm{dm}^{-3}\right)$ & 0,8 & & 0,3 & 0,44 & & 0,25 \\
\hline
\end{tabular}

cada material para obtenção de 15 plantas viáveis por metro linear, espaçadas a $0,70 \mathrm{~m}$ entre linhas simples de cultivo e semeadas manualmente a uma profundidade média de $3 \mathrm{~cm}$ nos dias 26 e 28 de outubro de 2011. O controle de plantas daninhas foi realizado com o uso do herbicida sistêmico Imazapique ( 140 g p. c. ha $\left.{ }^{-1}\right)$ e para invasoras remanescentes procedeu-se ao controle manual; daí cultivou-se o amendoim sem o emprego da irrigação.

Durante o desenvolvimento da cultura foram realizadas pulverizações de inseticidas e fungicidas quando se observaram os primeiros sintomas e pragas na área. No manejo de doenças foi utilizado o fungicida sistêmico composto por azoxistrobina e ciproconazol na dose de $60+24 \mathrm{~g}$ i. a. ha ${ }^{-1}$, respectivamente, associado a $0,5 \%$ de um adjuvante específico recomendado pelo fabricante e também o fungicida de contato clorotalonil $(1,5$ $\mathrm{kg}$ i. a. ha ${ }^{-1}$ ) para o controle de manchas foliares (Cercospora arachidicola e Cercosporidium personatum) e da verrugose (Sphaceloma arachidis).

O manejo de insetos praga foi realizado com lambda cialotrina + tiametoxan $\left(106+141 \mathrm{~g}\right.$ i. a. ha ${ }^{-1}$ respectivamente) e diflubenzuron (20 g i. a. ha ${ }^{-1}$ ) visando ao controle de Enneothrips flavens e Stegasta bosquella. Todas as aplicações foram realizadas com $200 \mathrm{~L} \mathrm{ha}^{-1}$ de calda, umidade relativa do ar acima de $55 \%$ e temperatura não superior a $30^{\circ} \mathrm{C}$. 
A colheita foi realizada no estádio $\mathrm{R}_{9}$, quando $70 \%$ das vagens apresentaram coloração marrom na face interna das valvas, sementes de cor característica do tegumento e teor de água em torno de $40 \%$. Contou-se o número total de plantas da área útil de cada unidade experimental, seguindo com o arranquio manual das plantas que foram submetidas à secagem ao sol. A altura de plantas foi determinada avaliando-se dez plantas na área útil central desde a base até o ápice da planta com auxílio de uma régua graduada. $\mathrm{O}$ número de ginóforos por planta foi avaliado pela contagem manual em dez plantas, na ocasião da colheita.

Também foram mensurados ginóforos mal formados, como sendo ginóforos emitidos que chegaram a penetrar no solo e vagens muito pequenas que não chegaram a desenvolver grãos.

O número de vagens por planta correspondeu à relação entre o número total de vagens colhidas por dez plantas amostradas aleatoriamente na área útil da unidade experimental. O número de sementes por vagem foi obtido pela contagem manual das sementes em dez vagens de dez plantas em cada unidade experimental. A massa média de 1.000 grãos foi determinada pela média de oito subamostras de 100 sementes por unidade experimental. A produtividade de grãos em $\mathrm{kg} \mathrm{ha}^{-1}$ foi calculada com base na produção da área útil total das subparcelas obtendo-se, também, o índice de rendimento de grãos (IRG) determinado através da Eq. 1.

$$
\operatorname{IRG}(\%)=\frac{\mathrm{MG}}{\mathrm{MV}} \times 100
$$

em que:

IRG - índice de rendimento de grãos em porcentagem, \%

MG - massa de grãos, $g$

MV - massa de vagens, $g$

Os resultados obtidos foram submetidos à análise de variância e, constatada significância a nível de 0,05 , procedeu-se à aplicação do teste de Tukey em nível de 0,05 de probabilidade pelo aplicativo computacional SAEG.

\section{Resultados e Discussão}

Não houve diferença significativa para o número de plantas por área entre os fatores e tratamentos isolados nem para a interação para ambos os locais estudados; assim, o estande médio foi de 208.870 plantas ha $^{-1}$ em Marechal Cândido Rondon e 206.080 plantas ha $^{-1}$ em Tupãssi.

$\mathrm{O}$ amendoim demanda pelo menos $600 \mathrm{~mm}$ de água durante o ciclo de desenvolvimento para obtenção de produções comerciais (Gillier \& Silvestre, 1970); obtiveram-se, durante a realização deste trabalho, volumes superiores porém ocorreram deficiências hídricas em fases críticas da cultura, como no mês de dezembro, onde se acumularam apenas 40,2 e 51,9 mm de chuva em Marechal Cândido Rondon e Tupãssi quando os cultivares se apresentavam no início do estádio reprodutivo (Figura 1). Esta restrição hídrica pode ter influenciado a produtividade dos materiais visto que, segundo Wrigth et al. (1994) cultivares de ciclo curto apresentaram menores rendimentos quando submetidos a estresses hídricos intermitentes e contínuos.

Observaram-se diferenças significativas $(\mathrm{p} \leq 0,05)$ para os componentes do rendimento do amendoim: altura de plantas, número de ginóforos malformados por planta, número de vagens por planta, número total de ginóforos por planta, número de grãos por vagem, índice de rendimento de grãos e produtividade, em função dos diferentes cultivares, em ambos os experimentos. Observou-se um comportamento independente dos fatores para essas variáveis visto que a interação sistemas de manejo de solo x cultivares, não foi significativa estatisticamente.

As maiores alturas de plantas e números de grãos por vagem foram observados para a cultivar IAPAR 25 Tição seguido do cultivar Cavalo, em Marechal Cândido Rondon e Tupãssi, respectivamente; as demais cultivares se apresentaram semelhantes (Tabelas 2 e 3). Esses resultados eram esperados devido ao tipo de crescimento de cada material em que cultivares de porte ereto apresentam maiores alturas de planta, acima de 40 cm e mais grãos por vagem (Santos, 2000; Peixoto et al., 2008).

Com relação ao número de estruturas reprodutivas avaliadas por planta, pode-se evidenciar que o cultivar IAC 503 apresentou o número de ginóforos $36 \%$ superior ao IAPAR 25 Tição, em Marechal Cândido Rondon (Tabela 2) e 41\% superior em Tupãssi (Tabela 3). Esta característica pode estar relacionada à constituição genética dos materiais. Esses resultados se comportaram da mesma forma para a variável número total de ginóforos por planta em que o cultivar IAC 503 correspondeu aos maiores índices.

Tabela 2. Altura de plantas, número de ginóforos mal-formados por planta, número de vagens por planta, número total de ginóforos por planta e número de grãos por vagem em função dos cultivares de amendoim estudado na safra 2011/2012 em Marechal Cândido Rondon, PR

\begin{tabular}{|c|c|c|c|c|c|}
\hline Cultivares & $\begin{array}{l}\text { Altura de plantas } \\
\text { (cm) }\end{array}$ & $\begin{array}{l}\text { Número de ginóforos mal } \\
\text { formados por planta }\end{array}$ & $\begin{array}{c}\text { Número de vagens } \\
\text { por planta }\end{array}$ & $\begin{array}{c}\text { Número total de } \\
\text { ginóforos por planta }\end{array}$ & $\begin{array}{l}\text { Número de grãos } \\
\text { por vagem }\end{array}$ \\
\hline Cavalo & $31,2 b^{\star}$ & $19,7 \mathrm{ab}$ & $33,7 \mathrm{c}$ & $53,4 \mathrm{c}$ & $2,9 \mathrm{~b}$ \\
\hline Runner IAC 886 & $25,8 \mathrm{C}$ & $19,4 a b$ & $40,5 \mathrm{a}$ & $59,9 \mathrm{ab}$ & $1,9 \mathrm{c}$ \\
\hline IAC 213 & $27,1 \mathrm{c}$ & $18,5 a b$ & $38,6 \mathrm{~b}$ & $57,1 \mathrm{~b}$ & $1,8 \mathrm{C}$ \\
\hline IAC 503 & $25,9 \mathrm{c}$ & $20,3 \mathrm{a}$ & $41,2 \mathrm{a}$ & $61,4 \mathrm{a}$ & $2,0 \mathrm{C}$ \\
\hline IAC Caiapó & $27,2 \mathrm{c}$ & $18,7 \mathrm{ab}$ & $40,6 \mathrm{a}$ & $59,3 a b$ & $2,0 \mathrm{C}$ \\
\hline IAPAR 25 Tição & $40,9 \mathrm{a}$ & $17,8 \mathrm{~b}$ & $27,3 d$ & $45,1 d$ & $3,3 \mathrm{a}$ \\
\hline DMS & 1,7 & 1,9 & 1,6 & 2,8 & 0,3 \\
\hline CV (\%) & 3,8 & 6,8 & 2,9 & 3,2 & 8,4 \\
\hline
\end{tabular}

*Médias seguidas da mesma letra minúscula na coluna não diferem entre si pelo teste de Tukey em nível de 0,05 de probabilidade 
Tabela 3. Altura de plantas, número de vagens por planta, número total de ginóforos por planta e número de grãos por vagem em função dos cultivares de amendoim estudado na safra 2011/2012 em Tupãssi, PR

\begin{tabular}{lcccc}
\hline \multicolumn{1}{c}{ Cultivares } & $\begin{array}{c}\text { Altura de plantas } \\
(\mathbf{c m})\end{array}$ & $\begin{array}{c}\text { Número de vagens } \\
\text { por planta }\end{array}$ & $\begin{array}{c}\text { Número total de } \\
\text { ginóforos por planta }\end{array}$ & $\begin{array}{c}\text { Número de grãos } \\
\text { por vagem }\end{array}$ \\
Cavalo & $31,8 \mathrm{~b}^{*}$ & $32,4 \mathrm{~b}$ & $51,5 \mathrm{c}$ & $2,8 \mathrm{~b}$ \\
Runner IAC 886 & $25,6 \mathrm{c}$ & $38,0 \mathrm{a}$ & $56,0 \mathrm{ab}$ & $1,9 \mathrm{~cd}$ \\
IAC 213 & $27,0 \mathrm{c}$ & $36,8 \mathrm{a}$ & $54,0 \mathrm{bc}$ & $1,7 \mathrm{~d}$ \\
IAC 503 & $25,9 \mathrm{c}$ & $40,1 \mathrm{a}$ & $59,4 \mathrm{a}$ & $2,0 \mathrm{C}$ \\
IAC Caiapó & $27,2 \mathrm{c}$ & $38,4 \mathrm{a}$ & $56,5 \mathrm{ab}$ & $2,0 \mathrm{c}$ \\
IAPAR 25 Tição & $40,7 \mathrm{a}$ & $25,6 \mathrm{c}$ & $42,1 \mathrm{~d}$ & $3,2 \mathrm{a}$ \\
DMS & 2,4 & 3,4 & 4,2 & 0,3 \\
CV (\%) & 5,2 & 6,3 & 5,2 & 7,6 \\
\hline
\end{tabular}

* Médias seguidas da mesma letra minúscula na coluna, não diferem entre si pelo teste de Tukey em nível de 0,05 de probabilidade

O número total de ginóforos por planta foi superior para os cultivares do grupo Virgínia, em ambos os locais (Tabelas 2 e 3). Referidos resultados estão relacionados diretamente com a produtividade (Tabela 4) e corroboram com dados obtidos por Bolonhezi (2007) ao relacionar o maior potencial produtivo de cultivares rasteiros pelo maior número de estruturas reprodutivas emitidas.

Diferenças significativas $(\mathrm{p} \leq 0,05)$ foram constatadas entre os sistemas de manejo de solo estudados apenas para o número de ginóforos mal-formados por planta nos dois experimentos; assim, o sistema de semeadura direta apresentou-se 4 e $2,8 \%$ superior ao sistema convencional em Marechal Cândido Rondon e Tupãssi, respectivamente (Figura 2). Esses resultados corroboram com as observações dos trabalhos de Colvin et al. (1988) e Wright (1991) que concluíram que a palhada constitui um impedimento físico à penetração dos ginóforos; nesses estudos, entretanto, tal como neste trabalho, este fator não ocasionou variação na produtividade de grãos entre os sistemas de manejo de solo adotados no cultivo do amendoim.

Por mais que o sistema de semeadura direta tenha proporcionado mais ginóforos mal- formados em todos os cultivares estudados, esta variável ainda não influenciou a produtividade de grãos do amendoim (Figura 2). Isto está relacionado, provavelmente, à maior disponibilidade hídrica no SSD, como observado por Bolonhezi (2007), o qual observou que após 10 dias sem chuvas superiores a $5 \mathrm{~mm}$ o SSD

Tabela 4. Índice de rendimento de grãos (IRG) e produtividade de grãos em função dos cultivares de amendoim estudados na safra 2011/2012 em Marechal Cândido Rondon e Tupãssi, PR, respectivamente

\begin{tabular}{|c|c|c|c|c|}
\hline \multirow[b]{2}{*}{ Cultivares } & \multicolumn{2}{|c|}{ Marechal Cândido Rondon } & \multicolumn{2}{|c|}{ Tupãssi } \\
\hline & $\begin{array}{l}\text { IRG } \\
(\%)\end{array}$ & $\begin{array}{l}\text { Produtividade } \\
\left(\mathrm{kg} \mathrm{ha}^{-1}\right)\end{array}$ & $\begin{array}{l}\text { IRG } \\
(\%)\end{array}$ & $\begin{array}{l}\text { Produtividade } \\
\left(\mathrm{kg} \mathrm{ha}^{-1}\right)\end{array}$ \\
\hline Cavalo & $80 \mathrm{a}$ & $3856 \mathrm{c}$ & $78 a^{*}$ & $3678 \mathrm{a}$ \\
\hline Runner IAC 886 & $77 \mathrm{bc}$ & $3966 \mathrm{abc}$ & $76 a b$ & $3769 a$ \\
\hline IAC 213 & $75 c$ & 3915 bc & $73 \mathrm{~b}$ & $3733 a$ \\
\hline IAC 503 & $78 \mathrm{~b}$ & $4110 \mathrm{a}$ & $77 \mathrm{a}$ & $3878 \mathrm{a}$ \\
\hline IAC Caiapó & $77 \mathrm{bc}$ & $4040 a b$ & $76 a b$ & $3823 \mathrm{a}$ \\
\hline IAPAR 25 Tição & $65 d$ & $2560 \mathrm{~d}$ & $65 c$ & $2573 b$ \\
\hline DMS & 2 & 152 & 3 & 210 \\
\hline CV (\%) & 2 & 3 & 3 & 4 \\
\hline
\end{tabular}

Médias seguidas da mesma letra minúscula na coluna, não diferem entre si pelo teste de Tukey em nível de 0,05 de probabilidade

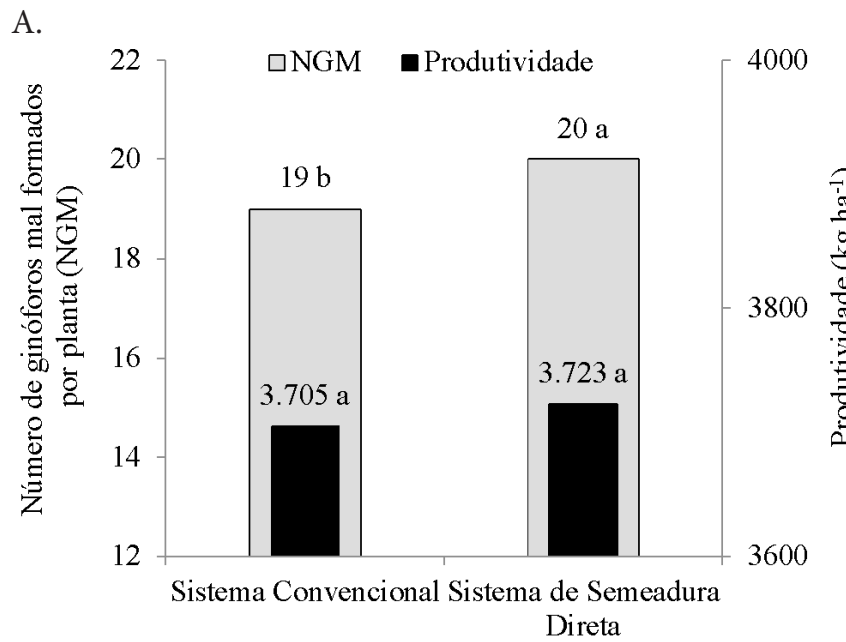

B.

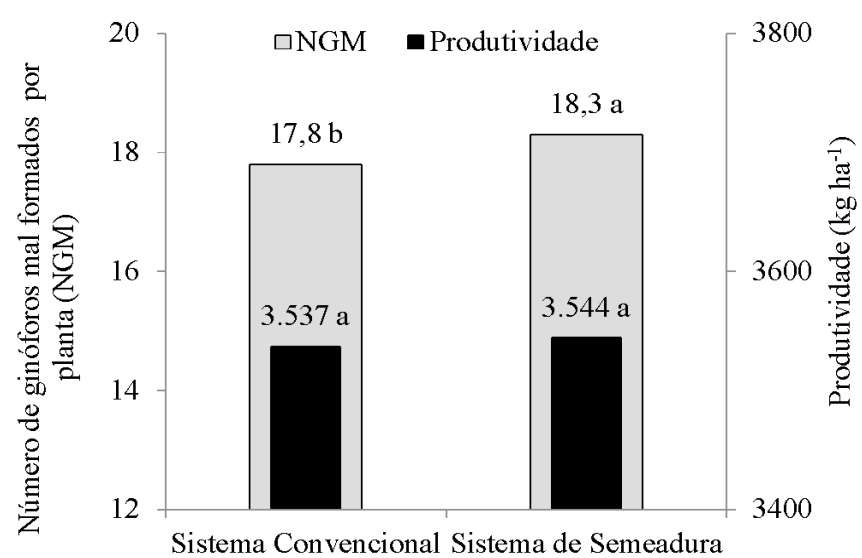

* Médias seguidas por letras minúsculas diferentes nas colwipasediferem entre si pelo teste de Tukey em nível de 0,05 de probabilidade

Figura 2. Número médio de ginóforos mal-formados e produtividade de grãos em função do sistema convencional e de semeadura direta na safra 2011/2012, A. Marechal Cândido Rondon, B. Tupãssi, PR

proporcionou maior conteúdo de água no solo na profundidade de $0-12 \mathrm{~cm}$; portanto, a diferença foi de 7 a $16 \%$ a mais que no convencional.

O fato de não haver interação dos sistemas de manejo de solo e cultivares, corrobora com os dados apresentados por Colvin \& Brecke (1988), que verificaram que o rendimento do amendoim em casca foi semelhante entre o preparo mínimo do solo e a semeadura direta para os cultivares em estudo. 
Desta forma, não é aconselhável afirmar que cultivares com porte rasteiro ("runner") são mais responsivas ao preparo de solo; disto, os autores concluíram que não há necessidade de desenvolver cultivares para sistemas conservacionistas e que a resposta aos níveis de revolvimento do solo independe do tipo de ramificação, se alternada (Virgínia) ou sequencial (Valência).

Os componentes da produção como número de vagens por planta, número total de ginóforos por planta e índice de rendimento de grãos, influenciaram diretamente e positivamente a produtividade dos cultivares, exceto para o cultivar Cavalo, no qual o menor número de vagens por planta reduziu a produtividade mesmo se observando o maior índice de rendimento de grãos para este cultivar em Marechal Cândido Rondon. Para essas variáveis os maiores valores foram obtidos para os cultivares IAC 503, IAC Caiapó e Runner IAC 886 , refletindo em um aumento de produtividade na ordem de aproximadamente $42 \%$ em relação ao cultivar IAPAR 25 Tição (Tabela 4).

Por outro lado, no município de Tupãssi a produtividade foi semelhante entre os cultivares de porte rasteiro diferindo apenas do cultivar de porte ereto IAPAR 25 Tição, o qual se apresentou $47 \%$ inferior à média dos demais materiais (Tabela 4 ).

Entre as variáveis estudadas a única que sofreu interação significativa entre os sistemas de manejo de solo e os cultivares foi a massa de mil grãos, em ambos os locais (Tabelas $5 \mathrm{e}$ 6). Os maiores valores para esta variável foram encontrados para o cultivar Cavalo, que se apresentou em média 47 e $43 \%$ superior ao cultivar IAPAR 25 Tição, em Marechal e Tupãssi, respectivamente. Foi possível observar, também, uma relação entre a massa de mil grãos e a produtividade exceto para o cultivar Cavalo; esta ocorrência se deve, provavelmente, ao menor número de vagens e ginóforos por planta, contabilizados para este cultivar.

O índice de rendimento de grãos não foi influenciado pelos sistemas de manejo de solo porém em termos absolutos este se apresentou aproximadamente 5 e $4 \%$ superior no SSD em relação ao sistema convencional em Marechal Cândido Rondon e Tupãssi. Mencionados resultados são distintos da maioria das pesquisas publicadas (Grichar \& Smith, 1991; Wright \& Porter, 1991; Jordan et al., 2001), as quais evidenciaram perdas de $3 \%$ no rendimento de grãos nos sistemas conservacionistas.

Em termos absolutos a produtividade de grãos foi superior no sistema de semeadura direta em aproximadamente $1 \% \mathrm{em}$ ambos experimentos (Figura 2). Esses resultados contradizem pesquisas realizadas por Wilcut et al. (1987); Grichar \& Boswell (1987); Colvin et al. (1988); Wilcut et al. (1990); Wright \& Porter (1991) e Jordan et al. (2001), os quais relatam perdas de 19 a $62 \%$ no rendimento de grãos nos sistemas conservacionistas estudados em condições norte-americanas.

Por outro lado, os resultados encontrados neste trabalho corroboram com os encontrados por Hartzog \& Adams (1989), Tasso Júnior (2003), Bolonhezi et al. (2007) e Crusciol \& Soratto (2007), os quais não observaram diferenças na produção do amendoim entre diferentes sistemas de cultivo sob variadas coberturas de solo. Ressalta-se, ainda, que Bolonhezi et al. (2005) afirmaram que a produção de grãos de amendoim no sistema plantio direto sobre palhada de cana-de-açúcar, foi $30 \%$ superior à cultivada no sistema convencional, mesmo com redução na população final de plantas, provavelmente em consequência da atenuação dos efeitos da deficiência hídrica proporcionada pela manutenção de palha na superfície do solo. Além dos componentes de produção, Godsey et al. (2011) relatam que o sistema de semeadura direta supera em US\$ 179 a receita de produção quando comparado ao sistema convencional de manejo de solo.

Avaliando a temperatura e o conteúdo de água no solo para amendoim com e sem palhada, Ramakrishna et al. (2006) concluíram que em período seco a presença de palhada proporciona uma redução de $22 \%$ nas perdas de água do solo e que esses resultados são observados também por Bolonhezi (2007) ao inferiu que a palhada no manejo plantio direto

Tabela 5. Massa de mil grãos (g) em função de sistemas de manejo do solo e de seis cultivares de amendoim, na safra 2011/2012 em Marechal Cândido Rondon, PR

\begin{tabular}{|c|c|c|c|c|c|c|c|}
\hline \multirow{2}{*}{$\begin{array}{c}\text { Sistema de manejo } \\
\text { do solo }\end{array}$} & \multicolumn{6}{|c|}{ Cultivares } & \multirow{2}{*}{$\begin{array}{l}\text { Média } \\
\text { sistemas }\end{array}$} \\
\hline & Cavalo & Runner IAC 886 & IAC 213 & IAC 503 & IAC Caiapó & IAPAR 25 Tição & \\
\hline \multicolumn{8}{|c|}{ Massa de mil grãos (g) } \\
\hline Sistema convencional & $740,1 \mathrm{Aa}$ & $612,4 \mathrm{Ba}$ & $542,4 \mathrm{Cb}$ & $618,1 \mathrm{Ba}$ & $612,9 \mathrm{Ba}$ & $479,8 \mathrm{Da}$ & 600,9 \\
\hline Sistema de semeadura direta & $733,5 \mathrm{Aa}$ & $611,7 \mathrm{BCa}$ & $581,6 \mathrm{Ca}$ & $620,8 \mathrm{Ba}$ & $618,0 \mathrm{Ba}$ & $483,4 \mathrm{Da}$ & 608,2 \\
\hline Média cultivares & 736,8 & 612,1 & 562,0 & 619,4 & 615,5 & 481,6 & \\
\hline CV $(\%)$ & \multicolumn{6}{|c|}{2,4} & \\
\hline
\end{tabular}

*Médias seguidas da mesma letra maiúscula na linha e minúscula na coluna, não diferem entre si pelo teste de Tukey a 0,05 de probabilidade

Tabela 6. Massa de mil grãos (g) em função de sistemas de manejo do solo e de seis cultivares de amendoim, na safra 2011/2012 em Tupãssi, PR

\begin{tabular}{llccccc}
\hline \multicolumn{1}{c}{\begin{tabular}{c} 
Sistema de manejo \\
\multicolumn{1}{c}{ do solo }
\end{tabular}} & Cavalo & Runner IAC 886 & IAC 213 $\begin{array}{c}\text { Cultivares } \\
\text { IAC 503 }\end{array}$ & IAC Caiapó & Média \\
\cline { 2 - 5 } IAPAR 25 Tição & Massa de mil grãos $(\mathrm{g})$ & \\
sistemas
\end{tabular}

* Médias seguidas da mesma letra maiúscula na linha e minúscula na coluna, não diferem entre si pelo teste de Tukey a 0,05 de probabilidade 
contribuiu para aumentar a disponibilidade de água para as cultivares de amendoim refletindo também em aumentos no rendimento de grãos.

Considerando os resultados obtidos neste trabalho e os demais estudos já realizados para a cultura do amendoim, é importante destacar a possibilidade de semear o amendoim em condições brasileiras no sistema plantio direto em sucessão à cultura da aveia, do milheto, braquiária ou panicum (Crusciol \& Soratto, 2007; Bolonhezi et al., 2007) ou mesmo com grande quantidade de palha na superfície, como em áreas de renovação de canaviais (Bolonhezi et al., 2007; Tasso Júnior, 2003), sem que haja prejuízo no estabelecimento e na produtividade da cultura, além de todos os benefícios proporcionados por este sistema de manejo de solo com o passar dos anos.

\section{Conclusões}

1. Não houve diferença entre os sistemas de manejo conservacionista e convencional na produção de vagens e grãos, no número de estruturas reprodutivas nem no índice de rendimento de grãos do amendoim nos dois locais avaliados.

2. As maiores produtividades foram obtidas pelos cultivares do tipo Virgínia independentemente do tipo sistema de manejo de solo, sendo IAC 503, IAC Caiapó, IAC 213, Runner IAC 886 e Cavalo, respectivamente, em Marechal Cândido Rondon.

3. No município de Tupãssi a produtividade de grãos variou somente entre os tipos de ramificação dos materiais sendo os maiores valores observados para cultivares ramificação alternada (Virgínia).

\section{Literatura Citada}

Bertol, O. J.; Rizzi, N. E.; Bertol, I.; Roloff, G. Perdas de solo e água e qualidade do escoamento superficial associadas à erosão entre sulcos em área cultivada sob semeadura direta e submetida às adubações mineral e orgânica. Revista Brasileira de Ciência do Solo, v.31, p.781-792, 2007.

Bolonhezi, D. Sistemas de manejo conservacionista do solo para cultivares de amendoim em sucessão à cana crua e pastagens. Jaboticabal: UNESP, 2007. 170p. Tese Doutorado

Bolonhezi, D.; Mutton, M. A.; Martins, A. L. M. Sistemas conservacionistas de manejo de solo para amendoim cultivado em sucessão à cana crua. Pesquisa Agropecuária Brasileira, v.42, p.939-947, 2007.

Bolonhezi, D.; Santos, R. C. dos; Godoy, I. J. de. Manejo cultural do amendoim. In: Santos, R. C. dos. O agronegócio do amendoim no Brasil. Campina Grande: Embrapa Algodão, Cap. 5, 2005. p.193-244.

Cassol, E. A.; Denardin, J. E.; Kochhann, R. A. Sistema plantio direto: Evolução e implicações sobre a conservação do solo e da água. In: Ceretta, C. A.; Silva, L. S.; Reichert, J. M. Tópicos em ciência do solo. Viçosa: Sociedade Brasileira de Ciência do Solo, 2007. Cap. 3, p.333-370.
Colvin, D. L.; Brecke, B. J. Peanut cultivar response to tillage systems. Peanut Science, v.15, p.21-24, 1988.

Colvin, D. L.; Brecke, B. J.; Whitty, E. B. Tillage variable for peanut production. Peanut Science, v.15, p.94-97, 1988.

CONAB - Companhia Nacional de Abastecimento. <http://www. conab.gov.br/download/safra/Primeiro_Levantamento_ Amendoim_2012-07 junho12.pdf>.8 Jun. 2012.

Crusciol, C. A. C.; Soratto, R. P. Nutrição e produtividade do amendoim em sucessão ao cultivo da plantas de cobertura no sistema de plantio direto. Pesquisa Agropecuária Brasileira, v.42, p.1553-1560, 2007.

EMBRAPA - Empresa Brasileira de Pesquisa Agropecuária. Centro Nacional de Pesquisa de Solos. Sistema brasileiro de classificação de solos. 2. ed. Rio de Janeiro: Embrapa Solos, 2006. 306p.

Gillier, P.; Silvestre, P. El cacahuete o maní. Madrid: Editorial Blume, 1970. 281p.

Godoy, I. J.; Morais, S. A.; Zanotto, D.; Santos, R. C. Melhoramento em Amendoim In: Borém, A. Melhoramento de espécies cultivadas, Viçosa: UFV, Cap. 4, 2005. p.54-95.

Godsey, C. B.; Vitale, J.; Mulder, P. G.; Armstrong, J. Q.; Damicone, J. P.; Jackson, K.; Suehs, K. Reduced tillage practices for the Southwestern US peanut production region. Peanut Science, v.38, p.41-47, 2011.

Grichar, W. J.; Boswell, T. E. Comparison of no-tillage, minimum, and full tillage cultural practices on peanuts. Peanut Science, v.4, p.101-103, 1987.

Grichar, W. J.; Smith, O. D. Effects of tillage systems on Southern blight and pod yield of five runner peanut genotypes. Peanut Science, v.18, p.144-147, 1991.

Hartzog, D. L.; Adams, J. F. Reduced tillage for peanut production. Soil \& Tillage Research, v.14, p.85-90, 1989.

Jordan, D. L.; Barnes, J. S.; Bogle, C. R.; Naderman, G. C.; Roberson, G. T.; Johnson, P. D. Peanut response to tillage and fertilization. Agronomy Journal, v.93, p.1125-1130, 2001.

Llanillo, R. F.; Richart, A.; Tavares Filho, J.; Guimarães, M. F.; Ferreira, R. R. M. Evolução de propriedades físicas do solo em função dos sistemas de manejo em culturas anuais. Semina: Ciências Agrárias, v.27, p.205-220, 2006.

Panachuki, E.; Alves Sobrinho, T.; Vitorino, A. C. T.; Carvalho, D. F.; Urchei, M. A. Avaliação da infiltração de água no solo, em sistema de integração agricultura-pecuária, com uso de infiltrômetro de aspersão portátil. Acta Scientiarum. Agronomy, v.28, p.129-137, 2006.

Peixoto, C. P.; Gonçalves, J. A.; Peixoto, M. F. S. P.; Carmo, D. O. Características agronômicas e produtividade de amendoim em diferentes espaçamentos e épocas de semeadura no recôncavo baiano. Bragantia, v.67, p.673-684, 2008.

Porter, D. M.; Wright, F. S. Early leafspot of peanuts: Effect of conservational tillage practices on disease development. Peanut Science, v.18, p.76-79, 1991. 
Prando, M. B.; Olibone, D.; Olibone, A. P. E.; Rosolen, C. A. Infiltração de água no solo sob escarificação e rotação de culturas. Revista Brasileira de Ciência do Solo, v.34, p.693$700,2010$.

Ramakrishna, A.; Tam, H. M.; Wani, S. P.; Long, T. D. Effect of mulch on soil temperature, moisture, weed infestation and yield of groundnut in northern Vietnam. Field Crops Research, v.95, p.115-125, 2006.

Santos, R. C. BRS 151 L-7: Nova cultivar de amendoim para as condições do Nordeste brasileiro. Pesquisa Agropecuária Brasileira, v.35, p.665-670, 2000.

Tasso Júnior, L. C. Cultura de soja, milho e amendoim sob diferentes sistemas de manejo do solo em área com palha residual de colheita mecanizada de cana crua. Jaboticabal: UNESP, 2003. 157p. Dissertação Mestrado
Wilcut, J. W.; Wehtje, G. R.; Colvin, D. L.; Patterson, M.G. Economic Assessment of herbicide systems for minimumtillage peanuts. Peanut Science, v.14, p.83-86, 1987.

Wilcut, J. W.; Wehtje, G. R.; Hicks, T. V. Evaluation of herbicide systems in minimum and conventional tillage peanuts (Arachis hypogaea). Weed Science, v.38, p.243248, 1990.

Wright, F. S. Alternate tillage practices for peanut production in Virginia. Peanut Science, v.18, p.9-11, 1991.

Wright, F. S.; Porter, D. M. Digging date and conservational tillage influence on peanut production. Peanut Science, v.18, p.72-75, 1991.

Wright, G. C.; Rao, R. C. N.; Farquhar, G. D. Water-use efficiency and carbon isotope discrimination in peanut under water deficit conditions. Crop Science, v.34, p.92-97, 1994. 